\title{
INDAHNYA PANGGILAN TUHAN Butir-butir Refleksi Surat Apostolik Paus Fransiskus dalam Tahun Hidup Bakti
}

\author{
Sihol Situmorang*
}

\begin{abstract}
Abstrak
Tak bisa dipungkiri bahwa tarekat religius atau hidup bakti adalah harta yang tak tergantikan bagi Gereja. Kehadiran dan sumbangannya sungguh telah mewarnai dan menghiasi Gereja dan perutusannya sepanjang masa. Kaum religius laksana garda depan bagi karya misioner Gereja lewat karya pastoral, pendidikan, sosial maupun kesehatan. Kesadaran akan sumbangan besar kaum religius inilah kiranya yang mendorong pemimpin Gereja senantiasa memberi dukungan kepada hidup bakti dengan menerbitkan sejumlah dokumen penting, khususnya sejak Konsili Vatikan II. Gereja berharap bahwa kaum religus berbuah lebih subur lagi untuk memperlihatkan keindahan, kesuburan dan kesempurnaan Kerajaan Allah. Paus Fransiskus menetapkan tahun 2015 sebagai Tahun Hidup Bakti sebagai suatu ajakan untuk semakin menghargai sumbangan karisma dan kesaksian kaum religius. Tahun ini menjadi momentum untuk bersyukur sekaligus kesempatan untuk berefleksi bagi tarekat hidup bakti secara khusus dan bagi seluruh Gereja secara umum. Dengan demikian tugas perutusan yang diterima dari Sang Misionaris Agung lebih berbuah lagi.
\end{abstract}

Kata-kata kunci: Gereja, hidup bakti, syukur, sukacita, Injil, kenabian, pengharapan, persekutuan, komunitas, membangunkan dunia.

\section{Pengantar}

Dalam setiap zaman ada pria dan wanita yang, karena taat kepada panggilan Bapa dan dorongan Roh, berani mengikuti Kristus dan mengabdikan diri kepada Allah dengan memusatkan perhatian pada perkara-perkara Tuhan. ${ }^{1}$ Meneladani semangat hidup apostolik, mereka

1 Konsili Vatikan II, "Dekrit Tentang Pembaharuan dan Penyesuaian Hidup Religius" (PC), dalam Dokumen Konsili Vatikan II, diterjemahkan oleh R. Hardawirjana (Jakarta: Dokumentasi dan Penerangan KWI-Obor, 1993), no. 1. 
meninggalkan segala sesuatu, agar dengan bantuan Roh Kudus melayani Tuhan dan umat beriman. Dengan cara hidup yang khusus, kaum religius turut serta menjadikan misteri Allah tetap bersinar dan misi Gereja terlaksana dengan cara yang khas. ${ }^{2}$

Hidup bakti adalah suatu bentuk/cara hidup khusus bagi mereka yang mengalami disapa secara pribadi oleh Allah dan menanggapinya secara unik. Sapaan ini tiada lain adalah cinta yang membuat seorang religius kuat, bersemangat dan senantiasa gembira dalam menghayati hidup baktinya. Karena cinta yang diperoleh dari perjumpaan pribadi dengan Tuhan, seorang religius mengalami sentuhan rohani dan terdorong untuk menjadi nabi yang siap menjadi pendengar dan pelaku sabda. Panggilan hidup bakti adalah panggilan untuk menjadi mistikus, yang mendalami hidup doa, dan sekaligus nabi, yang peka terhadap tanda-tanda zaman. ${ }^{3}$

\section{Penetapan Tahun Hidup Bakti}

Dalam pertemuan dengan para Pemimpin Umum Tarekat Religius di Roma tgl. 27-29 November 2013, Paus Fransiskus mencanangkan tahun 2015 sebagai Tahun Hidup Bakti. Penetapan ini dilatarbelakangi peringatan 50 tahun dua dokumen penting KV II yang secara khusus berbicara tentang hidup bakti, yakni Perfectae Caritatis dan Lumen Gentium. Tahun Hidup Bakti tersebut dimulai tgl. 21 November 2014, pada peringatan Santa Perawan Maria Dipersembahkan kepada Allah, yang oleh Paus Benediktus XVI ditetapkan sebagai Hari Pro Orantibus (untuk mereka yang berdoa), hari untuk secara khusus mengingat dan mendoakan kaum religius. ${ }^{4}$

Tahun Hidup Bakti ini akan ditutup pada pesta Yesus Dipersembahkan di Kenisah, tanggal 2 Februari 2016, yang oleh Yohanes Paulus II pada tahun 1997 ditetapkan sebagai Hari Doa Sedunia bagi Hidup Bakti. Tanggal ini dipilih mengingat bahwa pada pesta ini, yang secara tradisional disebut Misa dengan prosesi lilin,

\footnotetext{
2Mgr. Johannes Pujasumarta, Tahun Hidup Bakti 2015; http://www.dokpenkwi.org/2015/16/19/tahun-hidup-bakti-2105-suratgembala-uskup-agung-semarang/, 5 Oktober 2015.

${ }^{3}$ Mgr. Johannes Pujasumarta, Tahun Hidup Bakti 2015

4 Konferensi Waligereja Indonesia, Betapa Indah Panggilan-Mu, Tuhan;.http://www.mirifica.net/2014/11/15/pesan-kwi-menyongsongperayaan-hidup-bakti-2105/, 19 Oktober 2015.
} 
diwujudkan ramalan Simeon atas Yesus sebagai terang pewahyuan bagi bangsa-bangsa. Menurut Yohanes Paulus II, terang pembaktian diri total Yesus kepada Bapa memancar dengan lebih nyata dalam hidup bakti. Kaum hidup bakti itu ibarat teman-teman bijaksana yang menantikan Yesus, Sang Pengantin, dengan lampu bernyala. ${ }^{5}$

Penetapan Tahun Hidup Bakti ini didahului oleh sorotan dan renungan yang mendalam tentang makna iman-kepercayaan dalam hidup menggereja sepanjang tahun 2014, yang oleh Gereja semesta dirayakan sebagai Tahun Iman. Salah satu wujud hidup beriman itu adalah pembaktian diri secara utuh sebagai murid-murid Yesus. Tahun Hidup Bakti ini menjadi kesempatan yang sangat baik untuk kembali mendalami makna iman. Keunikan hidup bakti tak tersangkalkan dan tidak semua orang bisa memahami cara hidup yang secara khusus membaktikan diri kepada Tuhan dan sesama dengan menghidupi nasihat-nasihat Injil. ${ }^{6}$

Paus Fransiskus menegaskan bahwa Tahun Hidup Bakti ini tidak diperuntukkan hanya bagi Lembaga Hidup Bakti, tetapi untuk seluruh Gereja. Tahun ini kiranya menolong Gereja menemukan kembali hakekat hidup kristiani dan makna pengudusan lewat baptisan. Tahun ini menjadi sarana untuk men-shock kita akan keadaan pingsan rohani kita, sehingga bersama dengan kaum hidup bakti, kita dapat membangunkan dunia. Paus menghendaki agar seluruh Gereja mengalami tahun ini sebagai rahmat yang dengannya kita semua dapat menjadi lebih sadar akan karunia yang telah kita terima. ${ }^{7}$

Dalam konferensi pers untuk mengumumkan Tahun Hidup Bakti ini, Kardinal Joao Braz de Aviz, Prefek Kongregasi Institut Hidup Bakti dan Serikat Hidup Apostolik, menegaskan makna dan tujuan Tahun Hidup Bakti seperti tertuang dalam Surat Apostolik Paus Fransiskus kepada Semua Anggota Lembaga Hidup Bakti pada Peringatan Tahun Hidup Bakti. ${ }^{8}$

\footnotetext{
${ }^{5}$ Roger Landry, Commentary on Waking Up the World Through the Year for Consecrated Life. http://www.ncregister.com/daily-news/waking-up-theworld-through-the-year-for-consecrated-life/, 4 November 2015.

${ }^{6}$ William Chang, "Tahun Hidup Bakti" dalam Duta, 329/XXVI/Januari 2015, hlm. 45.

${ }^{7}$ Roger Landry, Commentary on Waking Up the World ...

8 News.va, http://www.news.va/en/news/year-of-consecrated-life-setfor-2015, 17, November 2015.
} 
Menanggapi penetapan Tahun Hidup Bakti tersebut, Konferensi Waligereja Indonesia (KWI) mengeluarkan pesan menyongsong Tahun Hidup Bakti 2015 dengan topik "Betapa Indah Panggilan-Mu, Tuhan" (bdk. Mzm 84:2). KWI melihat pencanangan Tahun Hidup Bakti ini sebagai kesempatan bagi putra-putri Gereja untuk mengobarkan semangat dan cinta agar semakin terbuka, lapang hati dan dengan keberanian iman menjawab panggilan Allah. KWI berpesan, "Tahun Hidup Bakti patutlah dijadikan kesempatan untuk merenung dan membarui komitmen kesetiaan kepada Tuhan, kepada pelayanan Gereja, kepada pemikiran dan cita-cita dasar pendiri tarekat masingmasing, dan kepada masyarakat zaman ini, meskipun ditemui banyak kesulitan." 9

Konferensi Pimpinan Tinggi Antar Religius Indonesia (KOPTARI), lembaga yang menaungi tarekat-tarekat religius Indonesia, dengan antuasias menanggapi seruan Paus Fransiskus dan KWI. Seiring dengan makna dan tujuan Tahun Hidup Bakti, KOPTARI memilih tema "Mensyukuri dan Memberi Kesaksian tentang Keindahan Mengikuti Kristus sebagai Religius". ${ }^{10}$

\section{$\log ^{11}$}

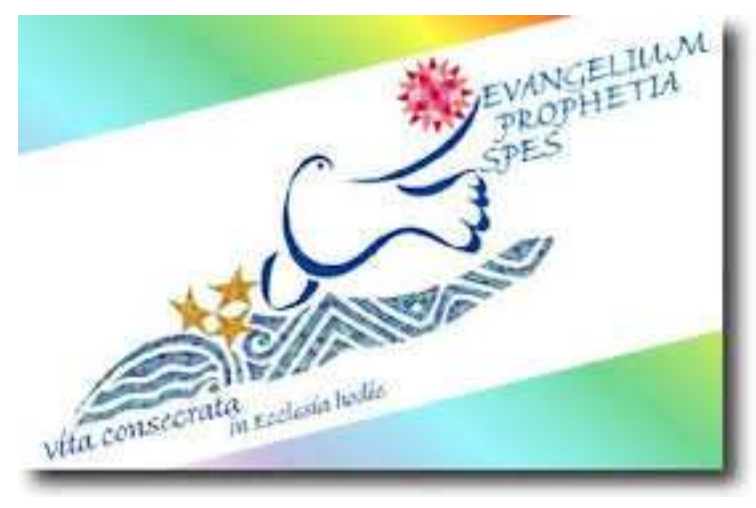

${ }^{9}$ Konferensi Waligereja Indonesia, Betapa Indah Panggilan-Mu, Tuhan ...

${ }^{10}$ Konferensi Waligereja Indonesia, Betapa Indah Panggilan-Mu, Tuhan ...

${ }^{11}$ Congregazione per gli istituti di Vita Consacrata e le società di Vita Apostolica, Vita consecrata in Ecclesia hodie Evangelium, Prophetia, Spes, http://www.vatican/va/roman-curia/congregation/ccscrlife/anno-vitaconscrata/logo-anno-vita-consacrata_en.htm, 24 November 2015. 
Tahun khusus ini berlogokan burung merpati yang seraya melayang di atas air menopang sebuah bola polyhedral pada satu sayap. Dari air keluar tiga bintang yang dilindungi oleh sayap lain. Lewat simbol-simbol, logo untuk Tahun Hidup Bakti, karya Carmela Boccasile ini, mengemukakan nilai-nilai fundamental hidup bakti. Lewat simbol itu dinyatakan karya Roh Kudus yang tiada hentinya sepanjang zaman untuk memperlihatkan kekayaaan praktik nasihat-nasihat Injil melalui aneka karisma. Roh Kudus selalu menghadirkan dalam Gereja dan dunia, dalam ruang dan waktu, misteri Kristus. ${ }^{12}$ Garis-garis yang membentuk gambar burung merpati dalam bahasa Arab berarti damai. Hidup bakti dipanggil untuk menjadi model perdamaian universal dalam Kristus.

\section{Simbol-simbol dalam Logo}

- Burung Merpati Melayang-layang di Atas Air

Merpati merupakan simbol klasik Roh Kudus, sumber hidup dan inspirator penciptaan. Simbol ini merujuk pada permulaan sejarah tatkala Roh Allah melayang-layang di atas air (bdk.Kej 1:2). Merpati yang melayang di atas lautan bergelombang melambangkan kesuburan yang tenang dan penuh harapan. Simbol-simbol di sekitarnya menyingkapkan tindakan penciptaan dan pembaruan oleh Roh. Merpati juga menggemakan pengudusan kemanusiaan Yesus lewat baptisan.

Air yang dilukis dengan menggunakan unsur-unsur mosaik menggambarkan kerumitan dan harmoni unsur-unsur manusiawi dan kosmis, unsur-unsur yang dijadikan erangan oleh Roh seturut rencana penuh rahasia dari Allah (bdk. Rom 8:26-27), sehingga unsur-unsur itu dapat bertemu secara ramah dan berbuah menuju ciptaan baru. Merpati melayang di antara gelombang sejarah, di antara air bah (bdk. Kej 8:814). Pria dan wanita yang pembaktiannya ditandai dengan Injil, senantiasa menjadi peziarah di atara para bangsa, mereka menghidupi karisma dan pelayanan yang beraneka ragam, seperti 'penguruspengurus yang baik dari kasih karunia Allah' (1Ptr 4:10). Kaum religius ditandai oleh Salib Kristus dan juga oleh kemartiran. Mereka diperlengkapi dengan kebijaksanaan Injil dan berjalan melalui sejarah.

12 Paus Yohanes Paulus II, Vita Consecrata (Hidup Bakti) no. 5, Seri Dokumen Gerejawi No.51, diterjemahkan oleh R. Hardawirjana (Jakarta: Departemen Dokumentasi dan Penerangan KWI, 2011), hlm. 12. Dokumen ini selanjutnya disingkat $V C$ dan diikuti nomor. 


\section{- Tiga Bintang}

Ketiga bintang menunjuk pada identitas hidup bakti sebagai confessio Trinitatis, signum fraternitatis dan servitium caritatis. Tiga bintang itu mengungkapkan hubungan melingkar yang ada dalam cinta Trinitarian, ke mana hidup bakti dipanggil untuk menghidupinya setiap hari di dunia. Tiga bintang itu juga mengisyaratkan tiga lingkaran cahaya yang digunakan dalam ikonografi Bizantin untuk menghormati Maria, Bunda Allah, Murid pertama Kristus dan model serta pelindung setiap hidup bakti.

- Bola polyhedral

Bola polyhedral kecil melambangkan planet dengan banyak jenis bangsa dan budaya, sebagaimana diterangkan Paus Fransiskus dalam Seruan Apostolik Evangelii Gaudium, no 236.13 Nafas Roh menopang dan membimbingnya menuju masa depan: suatu undangan bagi semua insan yang dibaktikan 'untuk menjadi pengemban Roh, pria dan wanita yang secara otentik bersifat rohani, mampu menanamkan dalam sejarah kesuburan yang terselubung'. ${ }^{14}$

\section{Kata-kata Penting}

Hidup Bakti dalam Gereja masa kini, Injil, Kenabian dan Pengharapan. Kata-kata kunci ini menyuguhkan hal-hal penting dalam identitas dan prospektif, pengalaman dan cita-cita, rahmat dan perjalanan yang telah dan sedang dihidupi kaum religius dalam Gereja sebagai umat Allah, ketika berjalan bersama dengan pelbagai bangsa dan budaya menuju masa depan.

${ }_{13}$ Paus Fransiskus, Evangelii Gaudium (Sukacita Injil)[EG], Seri Dokumen Gerejawi No. 94, diterjemahkan oleh F.X. Adisusanto, SJ dan Bernadeta Harini Tri Prasasti (Jakarta: Departemen Dokumentasi dan Penerangan KWI, 2015), no. 236, hlm. 236, "Dalam menghayati relasi antara yang universal/global dan lokal, dalam berpikir universal dan bertindak lokal, Paus Fransiskus menegaskan bahwa model kita bukanlah lingkaran, yang tidak melebihi bagian-bagiannya, di mana setiap titik berjarak sama dengan pusat, dan tidak ada perbedaan di antara titik yang satu dengan titik yang lain. Model kita ialah polyhedron, yang memantulkan konvergensi dari semua bagian-bagiannya, yang masing-masing mempertahankan kekhasannya."

${ }^{14} V C$, no. 6 . 
- Injil menunjuk aturan fundamental hidup bakti, sebagai sequela Christi sebagaimana diajarkan Injil. ${ }^{15}$ Pertama-tama sebagai kenangan hidup akan cara Yesus hidup dan bertindak16, kemudian sebagai kebijaksanaan hidup dalam terang nasihat-nasihat yang diberikan Tuhan kepada para murid-Nya. ${ }^{17}$ Injil menunjukkan jalan baru dan merupakan sumber kegembiraan. ${ }^{18}$

- Kenabian merupakan karakter hidup bakti sebagai bentuk khusus partisipasi dalam kenabian Kristus, yang oleh Roh Kudus dianugerahkan kepada seluruh Umat Allah. ${ }^{19}$ Tugas ini dilaksanakan dengan penyangkalan diri yang penuh keberanian dan dalam mewartakan kunjungan Allah yang baru melalui pencarian cara-cara baru untuk menerapkan Injil dalam sejarah dalam penantian akan kedatangan Kerajaan Allah. ${ }^{20}$

- Pengharapan adalah kepenuhan misteri orang kristen. Kita hidup dalam zaman yang serba tidak pasti. Harapan dibutuhkan dalam konteks kerapuhan kultural dan sosial, di saat cakrawala menjadi gelap karena orang-orang sudah tidak melihat tanda-tanda kehadiran Allah lagi. ${ }^{21}$ Hidup bakti senantiasa terarah ke masa depan (eskatologi); menyaksikan bahwa setiap harapan akan mencapai kepenuhannya yang definitif dan mengobah penantian kepada karya dan misi, bahwa Kerajaan Allah menjadi nyata di sini dan sekarang. ${ }^{22}$ Sebagai tanda pengharapan, kaum religius perlu dekat dengan umat manusia dan menunjukkan kasih, menjadi sebuah paradigma masa depan yang bebas dari segala penyembahan berhala.

Kaum religus, dikuatkan oleh kasih yang dicurahkan Roh Kudus (Rom 5:5), dipanggil untuk merangkul seluruh dunia dan menjadi kenangan cinta Trinitaris. Mereka adalah katalisator persekutuan dan kesatuan, penjaga yang berdoa pada puncak sejarah dan bersatu dengan

\section{${ }^{15}$ PC 2a.}

16 VC 22.

17 Konsili Vatikan II, "Lumen Gentium [LG]" dalam Dokumen Konsili Vatikan II, diterjemahkan oleh R. Hardawirjana (Jakarta: Dokumentasi dan Penerangan KWI-Obor, 1993), no. 42 hlm. 67-68.
${ }^{18} E G 1$.
${ }^{19}$ VC 84.
${ }^{20} \mathrm{VC} 84$.
${ }^{21}$ VC 85.
22 VC 27. 
kemanusiaan dalam kegelisahan dan dalam pencariannya yang hening akan Roh.

\section{Menyimak Pesan Paus Fransiskus}

Fransiskus, paus pertama dari Serikat Yesus, menulis pesan ini sebagai Pengganti Petrus dan pelaku Hidup Bakti. Beliau mengajak rekan-rekan kaum religius bersyukur kepada Bapa yang memanggil mereka mengikuti Yesus dengan merangkul Injil dan melayani Gereja.

\section{Tujuan Tahun Hidup Bakti}

- Mengenang masa lalu dengan penuh rasa syukur ${ }^{23}$

Paus Fransiskus menekankan pentingnya mengingat sejarah awal dan perkembangan sebuah karisma untuk menghidupkan kembali identitas, kesatuan, dan sense of belonging. Tuhan memanggil orangorang tertentu untuk mengikuti Kristus lebih dekat, menerjemahkan Injil ke dalam cara hidup tertentu, membaca tanda-tanda zaman dan menanggapi kebutuhan Gereja secara kreatif. Allah menganugerahi Gereja beragam karunia lewat hidup bakti dan panggilan kepada banyak pria dan wania selama berabad-abad. ${ }^{24}$

Dengan menceritakan sejarah, kita melihat nilai, semangat, pergumulan para pionir dan cara mereka mengantasi tantangan. Dengan itu kita memahami cita-cita, visi dan nilai yang mengilhami pendahulu agar dapat mengikuti langkah mereka seraya memikirkan prakarsa pengembangan karisma untuk masa kini maupun masa mendatang.

${ }^{23}$ Pope Francis, To All Consecrated People on The Occasion of The Year of Consecrated Life, Apostolic Letter of His Holiness Pope Francis, (Città del Vaticano: Libreria Editrice Vaticana, 2014), no. 1, hlm. 5-7.

${ }^{24}$ Roger Landry menulis, "Where would the Church be without Sts. Augustine, Benedict, Francis, Dominic, Ignatius, Vincent de Paul, Alphonsus Liguori and John Bosco? Or without Sts. Scholastica, Clare, Bridget, Angela Merici, Teresa of Avila, Jane de Chantal, Louise de Marillac, Elizabeth Seton, Frances Cabrini and Blessed Teresa of Calcutta? Or without the ceaseless prayer and the educational, medicinal and charitable works of so many consecrated men and women in every generation, including our own?" [Roger Landry, Commentary on Waking Up the World...] 
Dari penelusuran perjuangan para pendiri, khususnya panggilan dan tutunan Tuhan atas diri mereka, kita disadarkan bahwa kita hidup karena cinta Tuhan yang selalu menyertai kita. Kita semakin yakin bahwa Tuhan tidak akan meninggalkan kita. Kita sadar bahwa sumber dan dasar kehidupan kita adalah kasih Tuhan. Hal ini membuat kita makin setia dan mantap dalam kehidupan membiara. Merefleksikan dan mensyukuri masa lalu akan mendorong kita untuk menghargai jasa para pendahulu dan bertekad untuk mengembangkan nilai-nilai luhur yang kita warisi. Cara pengenangan yang benar adalah membuat hidup dan berbuah apa yang telah dimulai oleh para pendahulu serta mendoakan mereka. Kenangan yang hidup bermuara pada cara hidup yang lebih gembira. ${ }^{25}$ Melihat sejarah juga mengandung ajakan untuk bertobat dan membarui diri, sebab kita sadar akan ketidakkonsistenan, kelemahan bahkan pengabaian sejumlah aspek dari karisma kita.

- Menghidupi masa kini dengan penuh semangat (passion) ${ }^{26}$

Kenangan penuh syukur mendorong pemeluk hidup bakti untuk lebih setia melaksanakan panggilannya. Kaum religius diajak untuk secara radikal menghayati Injil dan membiarkan hidupnya ditantang, dibarui dan dituntun oleh Injil. Paus mengajak mereka untuk memeriksa kesetiaan pada perutusan dan mencermati sejauh mana pelayanan dan kehadiran mereka sejalan dengan apa yang diminta Roh dari pendiri dan relevan untuk masyarakat dan Gereja.

Terinspirasi oleh kesatuan para rasul dengan Kristus dan oleh persekutuan jemaat awal di Yerusalem dalam membangun komunitas, para pendiri berusaha untuk meniru model hidup injili, menjadi satu hati dan satu jiwa, dan bersukacita di hadapan Tuhan. Paus berharap agar kaum religius menjadi ahli dalam persekutuan, menjadi pria dan

25 Paul Suparno, "Mensyukuri Pengalaman Hidup Bakti" dalam Rohani 01/Januari/2015, hlm. 24-27. Dalam tulisan ini, Suparno mencermati bahwa hambatan hidup antusias muncul dari perasaan kurang dekat dan tidak didampingi oleh Tuhan, kurang beruntung dan kurang diberkati oleh Tuhan, sulit menerima kegagalan, minimnya dukungan dan kecenderungan membandingkan diri dengan orang lain.

${ }^{26}$ Pope Francis, To All Consecrated People..., no. 2, hlm. 7-11. 
wanita persekutuan, menjadi model komunitas yang menghargai perbedaan dan hidup sebagai saudara-i. ${ }^{27}$

Paus menegaskan bahwa karisma itu memang satu, namun perlu dihidupi sesuai dengan tempat, waktu dan pribadi. Karisma perlu dihidupi secara energik dan diinterpretasi secara kultural. Karisma bukanlah ibarat sebotol air sulingan. ${ }^{28}$

- Merangkul masa depan dengan penuh harapan²9

Kendati krisis (penurunan panggilan, penuaan anggota, krisis ekonomi, globalisasi) turut melanda hidup bakti, Paus berharap bahwa kaum religius tetap penuh dengan pengharapan mengarahkan pandangan kepada Kristus dan yakin bahwa Tuhan akan selalu menyertai. Gembira menghadapi masa depan tampak dalam semangat lepas bebas. Paus secara khusus menyapa generasi muda supaya lebih terlibat dalam dialog dengan generasi sebelumnya agar diperkaya dengan pengalaman dam kebijaksanaan mereka. Dengan itu mendapat ilham, energi dan entusiasme untuk merebut kembali idealisme para pendahulu. Akhirnya, seluruh komunitas dapat bergabung dalam menemukan cara baru menghayati Injil dan menanggapi secara lebih efektif kebutuhan untuk kesaksian dan pewartaan. ${ }^{30}$

\section{Harapan untuk Tahun Hidup Bakti}

- Tanda Sukacita ${ }^{31}$

Paus Fransiskus berharap agar kaum religus menjadi tanda sukacita, menunjukkan bahwa Allah adalah kepenuhan hidup. Persaudaraan sejati akan meningkatkan sukacita. Kendati ada pelbagai

27 Paul Suparno, "Menghidup Bakti secara Antusias" dalam Rohani 02/Februari/2015, hlm. 24-27.

28 Antonio Spadaro, Wake up the World, Conversation with Pope Francis about Religious Life, http://www.laciviltacattolica.it/articoli_download/extra/Wake_up_the_World.pdf, hlm. 5-8, 27 November 2015.

29 Pope Francis, To All Consecrated People..., no. 3, hlm. 11-13.

30 Paul Suparno, "Hidup Penuh Harapan" dalam Rohani 03/Maret/2015, hlm. 24-27. Menekuni hidup dengan harapan mengandaikan relasi dekat dengan Tuhan dan professionalisme dalam menghadapi tantangan masa depan. Zaman selalu berubah, maka metode pendekatan juga perlu dibarui.

${ }^{31}$ Pope Francis, To All Consecrated People..., no. 1, hlm. 14-16. 
kesulitan, kekecewaan dan kelemahan fisik akibat termakan usia, kaum religius harus bisa menemukan kebahagiaan sempurna. Tak seorang pun boleh menjadi masam, tidak gembira dan tidak puas, sebab 'seorang murid yang murung adalah murid kemurungan'.

Paus menegaskan bahwa hidup bakti berkembang bukan karena program brilian, tetapi karena orang yang kita jumpai menemukan kita sebagai pribadi yang memikat dan melihat kita sebagai pria dan wanita yang bahagia. Efektivitas apostolik hidup bakti tidak tergantung pada efisiensi metode, tetapi pada kefasihan dan mutu hidup kita sebagai kehidupan yang memancarkan sukacita dan keindahan menghayati Injil dengan mengikut Kristus.

Paus mengajak kaum religius menjadi saksi kasih persaudaraan, kesetiakawanan dan semangat berbagi. Untuk itu perlu menjaga komitmen, memerangi tendensi individualisme. Konfik dan perbedaan mustahil dihindarkan dan tidak ada artinya untuk membayangkan tinggal dalam satu komunitas tanpa konflik. Konflik, dalam arti tertentu bahkan perlu untuk menolong menghidup panggilan. Persaudaraan religius, dengan aneka perbedaan, merupakan pengalaman cinta yang mesti melewati konflik. ${ }^{32}$

- Membangunkan Dunia ${ }^{33}$

Tanda khas hidup bakti adalah kenabian lewat kesaksian dalam kemurahan hati. Paus berharap agar kaum religius bisa membangungkan dunia, ibarat membunyikan alarm bagi masyarakat untuk bertanya, apa yang tengah terjadi. Seorang religius dipanggil untuk hidup profetis yang menyalakan jalan menuju masa depan. Mereka memperlihatkan bagaimana Kerajaan Allah tampak dalam kesempurnaan. Seorang religius tidak boleh berhenti bersuara. Menjadi nabi dalam arti tertentu ibarat membuat ribut. Karisma kaum religius itu seperti ragi, yakni kenabian yang menyuarakan roh Injil. ${ }^{34}$

Kaum religius menyatakan sesuatu dan melangkah melebihi horizon duniawi. Mereka memiliki sesuatu untuk dikatakan kepada dunia masa kini. Perjumpaan dengan Tuhan dilanjutkan dengan perjumpaan dengan manusia yang membuka kemungkinan adanya

32 Antonio Spadaro, Wake up the World ... hlm. 10-12.

${ }^{33}$ Pope Francis, To All Consecrated People..., no. 2, hlm. 16-17..

${ }^{34}$ Antonio Spadaro, Wake up the World ... hlm. 5. 
transformasi. Kaum religius diharapakan menemukan cara dan ruang alternatif di mana berkembang pemberian diri, persaudaraan, perbedaan-perbedaan yang merangkul dan saling mengasihi. Secara berkesinambungan dan kreatif, mereka menafsirkan karisma agar menjadi ragi bagi masyarakat dan sebuah kota di atas bukit. Untuk membangunkan dunia, kaum religius sendiri pertama-tama harus bangkit. ${ }^{35}$

Paus juga menekankan bahwa kaum religius tak perlu takut berbuat salah atau bahkan berbuat dosa. Hidup itu pelik dan terdiri atas dosa dan rahmat. Siapa yang tidak berdosa, bukanlah manusia. Seorang religius yang menyadari diri sebagai orang lemah dan berdosa tetap diundang untuk memberi kesaksian. ${ }^{36}$

\section{- Ahli Persekutuan ${ }^{37}$}

Kaum hidup bakti, dengan spiritualitas persekutuan, diharapkan berada di garis depan untuk menjawab tantangan besar millenium baru: menjadikan Gereja sebagai rumah dan sekolah persekutuan. Persekutuan itu pertama dan terutama dihayati dalam komunitas. Kaum religius diharap menyikapi seruan paus yang cukup sering dikemukakan perihal kritik, gosip, iri hati, kecemburuan dan permusuhan yang harus dihindarkan. Mistik hidup bersama yang menjadikan hidup kita sebuah peziarahan suci menuntut sikap saling menerima, kepedulian, persekutuan kebaikan baik material maupun spiritual, koreksi persaudaraan dan menghormati yang lemah. Khususnya ketika komunitas kita bersifat internasional, kita perlu melihat cara kita berelasi dengan mereka yang berasal dari budaya yang berbeda. Setiap anggota mesti bebas mengatakan apa yang dia pikirkan,

${ }^{35}$ Antonio Spadaro, Wake up the World ... hlm. 2-3; Maria Cimperman, RSCJ, "Wake up the World! Celebrating the Year of Consecrated Life", http://rscjinternational.org/news/wake-world-celebrating-year-consecratedlife-cimperman.

${ }^{36}$ Antonio Spadaro, Wake up the World ..., hlm. 3.

${ }^{37}$ Pope Francis, To All Consecrated People..., no. 3, hlm. 17-19. 


\section{Sihol Situmorang, Indahnya Panggilan Tuhan}

diterima dengan karunia-karunia dalam dirinya, dan bersama-sama bertanggung jawab sepenuhnya. Ahli persekutuan dan pakar pemersatu.

Paus tidak menafikan fakta bahwa kita kadang begitu kejam, tergoda untuk mengkritik. Kaum Hidup Bakti diajak untuk tidak bertindak seperti menejer bila terjadi masalah dalam persaudaraan, tetapi harus melibatkan hati. "Persaudaraan itu indah dan manis. Kita mesti bersikap terhadap saudara dengan kelembutan ekaristik. Kita mesti peduli dengan konflik yang terjadi. Kelembutan hati menjadikan kita insan yang baik. Kelembutan hati yang kita timba dari Ekaristi tidak menyelubungi konflik dengan topeng, tetapi menolong kita untuk menghadapinya," kata Paus Fransiskus. ${ }^{38}$

Persekutuan itu juga kiranya menjangkau lembaga-lembaga yang berbeda dan bekerja sama dalam tingkat lokal dan global. Persekutuan dan perjumpaan dengan karisma dan panggilan lain dapat membuka sebuah jalan harapan. Untuk itu perlu dialog dan perjumpaan.

- Keluar dari diri sendiri dan pergi ke wilayah pinggiran ${ }^{39}$

Pergi ke seluruh dunia merupakan wejangan terakhir yang ditujukan Yesus kepada para murid dan kepada kita. Seluruh dunia, khususnya mereka yang kesulitan dan kehilangan harapan menanti kita. Paus berharap agar kaum religius tidak terkungkung dalam diri sendiri dan tersandera oleh pertengkaran-pertengkaran kecil. Masalah kita akan terselesaikan dengan membantu menyelesaikan masalah orang lain. Kaum Hidup Bakti dengan sukacita berani keluar dari zona rasa aman. Kita akan menemukan kehidupan dengan memberi kehidupan, harapan dengan memberikan harapan, kasih dengan memberikan kasih. Untuk itu perlu mencari dan meninjau kembali cara kerasulan yang sesuai dengan kebutuhan. Bagi Paus Fransikus, panggilan untuk berani keluar

\footnotetext{
38 Antonio Spadaro, Wake up the World ..., hlm. 11-12.

39 Pope Francis, To All Consecrated People..., no. 4, hlm. 20.
} 
dari diri sendiri, sebagaimana ditunjukkan oleh Abraham merupakan contoh bagi umat beriman dan secara khusus bagi kaum religius. ${ }^{40}$

Paus Fransiskus menyebut tiga hal yang menjadi tantangan bagi kaum Hidup Bakti bila diminta pergi ke wilayah pinggiran, yaitu marginalisasi, persoalan kultur dan pendidikan. Secara khusus paus menekankan perlunya menangani pendidikan dengan serius, sebab pendidikan adalah kunci bagi karya misi. ${ }^{41}$

- Melaksanakan Pelayanan seturut Kehendak Allah42

Paus mengharapkan agar kaum hidup bakti sungguh-sungguh memeriksa keberadaannya dalam kehidupan Gereja dan menanggapi tuntutan baru dan jeritan orang miskin. Tahun Hidup Bakti ini akan menjadi saat yang kaya akan rahmat Allah dan momen perubahan bila kita memiliki keprihatikan akan kebutuhan dunia dan kepatuhan pada bisikan Roh.

\section{Cakrawala Tahun Hidup Bakti ${ }^{43}$}

Paus Fransiskus tidak mengalamatkan surat ini hanya kepada kaum religius, tapi juga kepada seluruh Gereja. Paus mengharapkan agar

40 Pope Francis, Message of Pope Francis for the 52nd World Day on Prayer for Vocations,

https://w2.vatican.va/content/francesco/en/messages/vocations/documents/papafrancesco_20150329_52-messaggio-giornata-mondiale-vocazioni.html. "At the root of every Christian vocation we find this basic movement, which is part of the experience of faith. Belief means transcending ourselves, leaving behind our comfort and the inflexibility of our ego in order to centre our life in Jesus Christ. It means leaving, like Abraham, our native place and going forward with trust, knowing that God will show us the way to a new land. This "going forward" is not to be viewed as a sign of contempt for one's life, one's feelings, one's own humanity. On the contrary, those who set out to follow Christ find life in abundance by putting themselves completely at the service of God and his kingdom. The exodus experience is paradigmatic of the Christian life, particularly in the case of those who have embraced a vocation of special dedication to the Gospel. This calls for a constantly renewed attitude of conversion and transformation, an incessant moving forward, a passage from death to life like that celebrated in every liturgy, an experience of passover."

${ }^{41}$ Antonio Spadaro, Wake up the World ..., hlm. 13-14.

${ }^{42}$ Pope Francis, To All Consecrated People...., no. 5, hlm. 21-22.

${ }^{43}$ Pope Francis, To All Consecrated People...., no. 1-4, hlm. 23-28. 
umat beriman makin menyadari karunia berkat kehadiran kaum religius. Tahun Hidup Bakti juga menjadi momen bagi setiap komunitas kristen untuk bersyukur, mendekatkan diri, bersukacita, berbagi kesulitan dan membantu kaum hidup bakti. Tidak tertutup kemungkin bagi kerjasama ekumenisme hidup bakti dengan Gereja yang memiliki tradisi monastisisme dan ungkapan lain persaudaraan religius yang hadir dalam semua agama besar.

Paus meminta para uskup untuk menunjukkan perhatian khusus untuk menggalakkan di komunitas-komunitas mereka karisma yang berbeda-beda ini, mengingat bahwa Hidup Bakti adalah karunia yang lahir, tumbuh dan sepenuhnya diarahkan bagi Gereja. Hidup Bakti adalah jantung Gereja, sebuah unsur yang menetukan dalam perutusannya, yang mengungkapkan sifat terdalam panggilan kristen dan kerinduan Gereja sebagai mempelai untuk kesatuan dengan mempelai satu-satunya.

\section{Penutup}

Paus Fransiskus memercayakan Tahun Hidup Bakti ini kepada Maria, yang digelarinya Perawan pendengaran dan permenungan, murid pertama dari Puteranya. Kaum religius diajak mengarahkan pandangan kepada Maria, putri yang sangat dikasihi Bapa, model yang tak tertandingi bagi semua orang yang mengikuti Kristus dalam kasih Allah dan pelayanan kepada sesama. Maria adalah model unik bagi kaum religius. ${ }^{44}$

$$
====0000====
$$

${ }^{44}$ Pope Francis, To All Consecrated People...., no. 5, hlm. 28. 


\section{DAFTAR PUSTAKA}

Chang, William. "Tahun Hidup Bakti” dalam Duta, 329/XXVI/Januari 2015, hlm. 45.

Cimperman, Maria. Wake up the World! Celebrating the Year of Consecrated Life. http:// rscjinternational.org/news/wake-world-celebratingyear-consecrated-life-cimperman/

Congregazione per gli istituti di Vita Consacrata e le società di Vita Apostolica. Vita consecrata in Ecclesia hodie Evangelium, Prophetia, Spes. $\quad$ http://www.vatican/va/romancuria/congregation/ccscrlife/anno-vita-conscrata/logo-anno-vitaconsacrata_en.htm

Francis. Message of Pope Francis for the 52nd World Day on Prayer for Vocations,

https://w2.vatican.va/content/francesco/en/messages/vocations/document s/papa-francesco_20150329_52-messaggio-giornata-mondialevocazioni.html.

Francis. To All Consecrated People on The Occasion of The Year of Consecrated Life, Apostolic Letter of His Holiness Pope Francis. Città del Vaticano: Libreria Editrice Vaticana, 2014.

Fransiskus. Evangelii Gaudium (Sukacita Injil)[EG]. Seri Dokumen Gerejawi No. 94. Diterjemahkan oleh F.X. Adisusanto, SJ dan Bernadeta Harini Tri Prasasti. Jakarta: Departemen Dokumentasi dan Penerangan KWI, 2015.

Konsili Vatikan II. "Dekrit Tentang Pembaharuan dan Penyesuaian Hidup Religius" (PC), dalam Dokumen Konsili Vatikan II. Diterjemahkan oleh R. Hardawirjana. Jakarta: Dokumentasi dan Penerangan KWI-Obor, 1993.

Konsili Vatikan II. “Lumen Gentium” dalam Dokumen Konsili Vatikan II. Diterjemahkan oleh R. Hardawirjana. Jakarta: Dokumentasi dan Penerangan KWI-Obor, 1993.

Konferensi Waligereja Indonesia. Betapa Indah Panggilan-Mu, Tuhan; Pesan KWI Menyongsong Tahun Hidup Bakti 2015. 
Sihol Situmorang, Indahnya Panggilan Tuhan

http://www.mirifica.net/2014/11/15/pesan-kwi-menyongsongperayaan-hidup-bakti-2105/

Landry, Roger. Commentary on Waking Up the World Through the Year for Consecrated Life.http://www.ncregister.com/daily-news/wakingup-the-world-through-the-year-for-consecrated-life/

News.va. http://www.news.va/en/news/year-of-consecratedlife-set-for-2015

Paulus II, Yohanes. Vita Consecrata (Hidup Bakti). Seri Dokumen Gerejawi No.51. Diterjemahkan oleh R. Hardawirjana. Jakarta: Departemen Dokumentasi dan Penerangan KWI, 2011.

Paulus II, Yohanes. Redemptoris Donum, no. 14.

Pujasumarta, Johannes. Tahun Hidup Bakti 2015; Surat Gembala Keuskupan Agung Semarang. http://www.dokpenkwi.org/2015/16/19/tahun-hidup-bakti2105-surat-gembala-uskup-agung-semarang/

Spadaro, Antonio. Wake up the World, Conversation with Pope Francis about Religious Life. http://www.laciviltacattolica.it/articoli_download/extra/Wake_up_the_World.pdf.

Suparno, Paul. "Menghidup Bakti secara Antusias" dalam Rohani 02/Februari/2015, hlm. 24-27.

Suparno, Paul. "Mensyukuri Pengalaman Hidup Bakti" dalam Rohani 01/Januari/2015, hlm. 24-27.

Suparno, Paul. "Hidup Penuh Harapan" dalam Rohani 03/Maret/2015, hlm. 24-27. 